\title{
Tina: Empowerment Based Design for Domestic Violence Survivors Mobile Application
}

\author{
Emma Nuraihan Mior Ibrahim ${ }^{1 *}$,Azurawati Abdul Halim²,Fariza Hanis Abdul Razak ${ }^{3}$ \\ ${ }^{1,2,3}$ Faculty of Computer and Mathematical Sciences, Universiti Teknologi MARA, 40450 Shah Alam, \\ Selangor, Malaysia \\ emma@tmsk.uitm.edu.my ${ }^{1}$
}

Article History: Received: 10 November 2020; Revised: 12 January 2021; Accepted: 27 January 2021; Published online: 05 April 2021

\begin{abstract}
This paper presentsa preliminary work on empowerment-based design mobile application prototype for those living with or identified as domestic violence (DV) survivors in Malaysia.By using Design Thinking method, we developed a mobile application which acts as a social support platform for DV survivors especially to those who are reluctant or unwilling to seek help. The study was conducted with Women's Aid Organization (WAO), an NGO responsible for the provision of aid to domestic violence survivors in Malaysia. The aim of this project is to enhance TINA (Think I Need Aid) services provided by WAO.For the prototype design, the study proposed five (5) categories of empowerment features which include (i) screening and assessment, (ii) emergency response (iii) evidence reporting (iv) preventative and (v) self-efficacy andempowerment. The prototype was then tested and evaluated in terms of its functionality and practicality with 10 participants representing various stakeholders. A qualitative analysis was used to analyse the participant feedback. The paper concluded with discussion of the results and future works.
\end{abstract}

Keywords:Empowerment based Design, Domestic Violence (DV), Mobile Application, Design Thinking

\section{Introduction}

Violence Against Women (VAW) is defined by World Health Organization (WHO) as "any act of genderbased violence that results in, or is likely to result in, physical, sexual or psychological harm or suffering to women, including threats of such acts, coercion or arbitrary deprivation of liberty, whether occurring in public or in private life" (UN General Assembly, 1993).

VAW cuts across lines of race, religion, income, class, and culture and is compounded by discriminationon the grounds of ethnicity, sexual identity, social status, class and age (WHO, 2013; Williams, JR. et. al., 2016;Beyene, A.S. et. al., 2019; WAO, 2017a).A domestic violence (DV)victim is defined as someone who is still trapped in an abusive relationship whereas a DV survivor is defined as a former victim, someone having lived through previous episodes of DV(WAO, 2017a).

In the literature, common usage on terminologies of 'victim' and 'survivor' limitindividual self-agency and identity and recommends the replacement of both terminologies with 'person/woman/man who has experienced violence'. For the purpose of this study, the term DV survivor will be used to represent both victims and survivors and will discuss DV as previous traumatic occurrences for the survivor regardless of when the episode occurred.

According to a study conducted by Universiti Sains Malaysia (Shuib, R. et. al., 2013), nine percent of women in Peninsular Malaysia has experienced DV at some point in their lifetime. Between2000 to 2018, the number of DV cases in Malaysia steadily remains in the 3,000s(WAO, 2018b). Nevertheless, The Advocacy For Women's Rights In Malaysia has made significant advances over the past two decades in protecting survivors of DV through laws and policies as well as advocacy work by a coalition between NGOs and human rights defenders (refer Figure 1).

In 2014, WAO launched TINA (Think I Need Aid), a text message aid service comprising of both SMS and Whatsapp, to reach out to survivors of DV and women in crisis (Malay Mail Online, 2014). TINA is an extension of Hotline and takes theformofa'virtualfriend'ofWAO.TINAprovidesaveilofanonymityforsurvivors who may find 'calling a helpline' as a barrier or when speaking on the phone is calculatively dangerous, especially if the perpetrator is close enough tohear. As a 'friend', TINA appeals to the younger generation who prefers an informal chatwithafriendratherthanspeakingtoacounsellororsocialworker. 


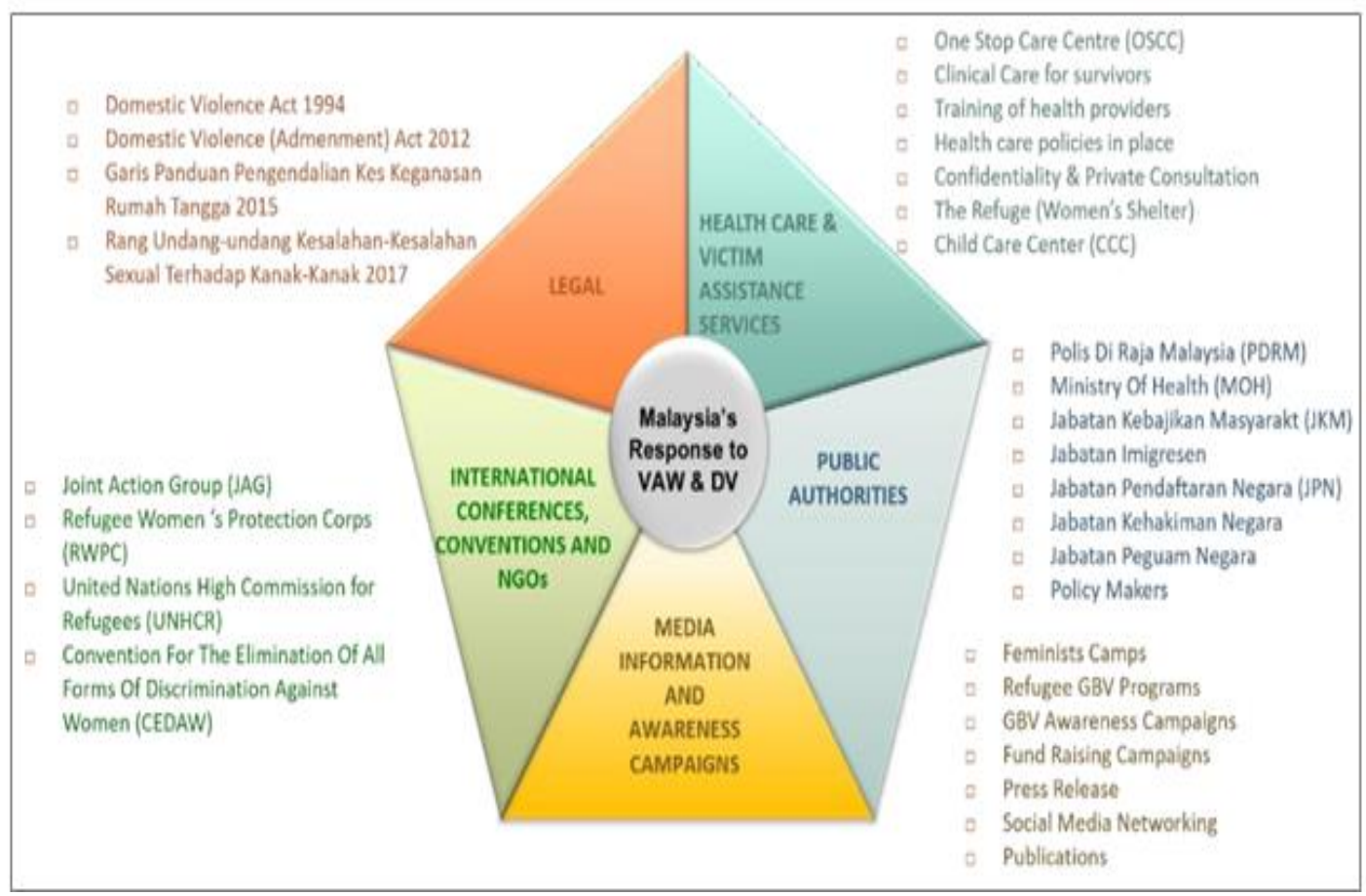

Figure 1.A Summary of Malaysia's Response to VAW and DV(KPWKM, 2015).

However, to date, neither web-based systems nor mobile applications that provide psychosocial assistance to DV survivors or psychological assistance by means of empowering them has been implemented in Malaysia. This is largely due to the lack of manpower, funds and resources within locals NGOs to develop a DV dedicated platform to address these issues. In Malaysia, addressing this issue is crucial as the number of DV cases are increasing every year (WAO, 2018b; Hussain et al., 2016; M. Abdul Ghani, 2014). The matter was made even more prevalent with the suspension of "MyDistress", an Emergency Response app by PDRM in 2013 (Malay Mail, 2013) whereas "Watch Over Me", the only mobile application for Malaysian Women is readily available (Digital News Asia, 2014).

Hence, we present TINA, a mobile application project that provides empowerment features on DV survivors (T. Padmapriya et al, 2020). For DV survivors, mobile phones may be a critical component to their safety planning and play a role in violence prevention (NNEDV, 2015; Dunlap, 2012; Dimond, J.P., et. al, 2011;Hussain et al., 2017; Bivens, R. \& Hasinoff, A.A., 2018). In this paper we discussed how to design, develop and evaluate TINA to empower survivors to make informed decisions and to be in control of their livelihood activities (Karapanos, 2015).In the psychological empowerment literature, empowerment at an individual level describes the empowering process where people create or receive opportunities to control their own destiny and influence the decisions that affect their lives. This process dependson the attributes such as selfefficacy, competence, belief, and perceived control that people have (Helmi, I., et. al, 2019; Zimmerman, 2000). In addition, research on this area have been gaining momentum in recent years with some developing conceptual frameworks for VAW and DV Survivors that featured empowerment process (Tarzia, L. et. al, 2016; Leech, H., 2015).

\section{Design And Implementation}

As the central attention in this study is empowerment, we decided to apply Design Thinking method(Lockwood, T \& Papke, E., 2017; Yeager, D.S., et.al., 2016)in the design and development process which has long governed research design in the context of self-administered psychological interventions (Yeager et al., 2016) (refer Figure 2). At the empathize phase, the design process was conducted collaboratively with WAO and DV survivors which they involved in brainstorming the app design content.WAO did a walkthrough of the existing process of handling DV cases ranging from Hotline calls, WhatsApp texts, SMS messages, and Case Management and provided insights on the usage of guidelines based established in the Garis Panduan Pengendalian Kes KeganasanRumahTanggabyKPWKM(2015).Wethen mappedtherequirementsaccording to the modified frameworks from (NNEDV, 2015; Leech, 2015; Tarzia. L., et. al., 2016; Murray, et al., 2016 and U.S Department of Defense, 2017). Theframeworkencompasses(i) Screening\&Assessment (ii) Emergency Response (iii) EvidenceReporting,Preventative,and(iv) SelfEfficacy\&Empowerment (refer Figure 3). These categories 
complement each other in creating a holistic mobile app for the empowerment of DV survivors in line with WAO's mission andvision. While in the ideation and prototype phase, the study started with a co-creation session with WAO where an affinity diagram for the prototype is delivered. This is followed by the identification of the major and subthemes, conceptualizing the thematic map, and identification of modules and submodules for TINA (refer Table 1). The prototype phase is achieved when TINA is developed using AppyPiemobile app builder(refer Figure 4). Finally, we tested TINA with eight WAO social workers highly experienced on DV which act assurrogateusersandtwoDVSurvivors. Weusedthe thinkaloudprotocolasthe test tool, with supporting documents including user informed consent form, user background questionnaire and user satisfactionquestionnaire. Due to anonymity, privacy and security matters of DV survivor's participation, we are only allowed to conduct the test with the chosen DV survivors recommended by WAO.

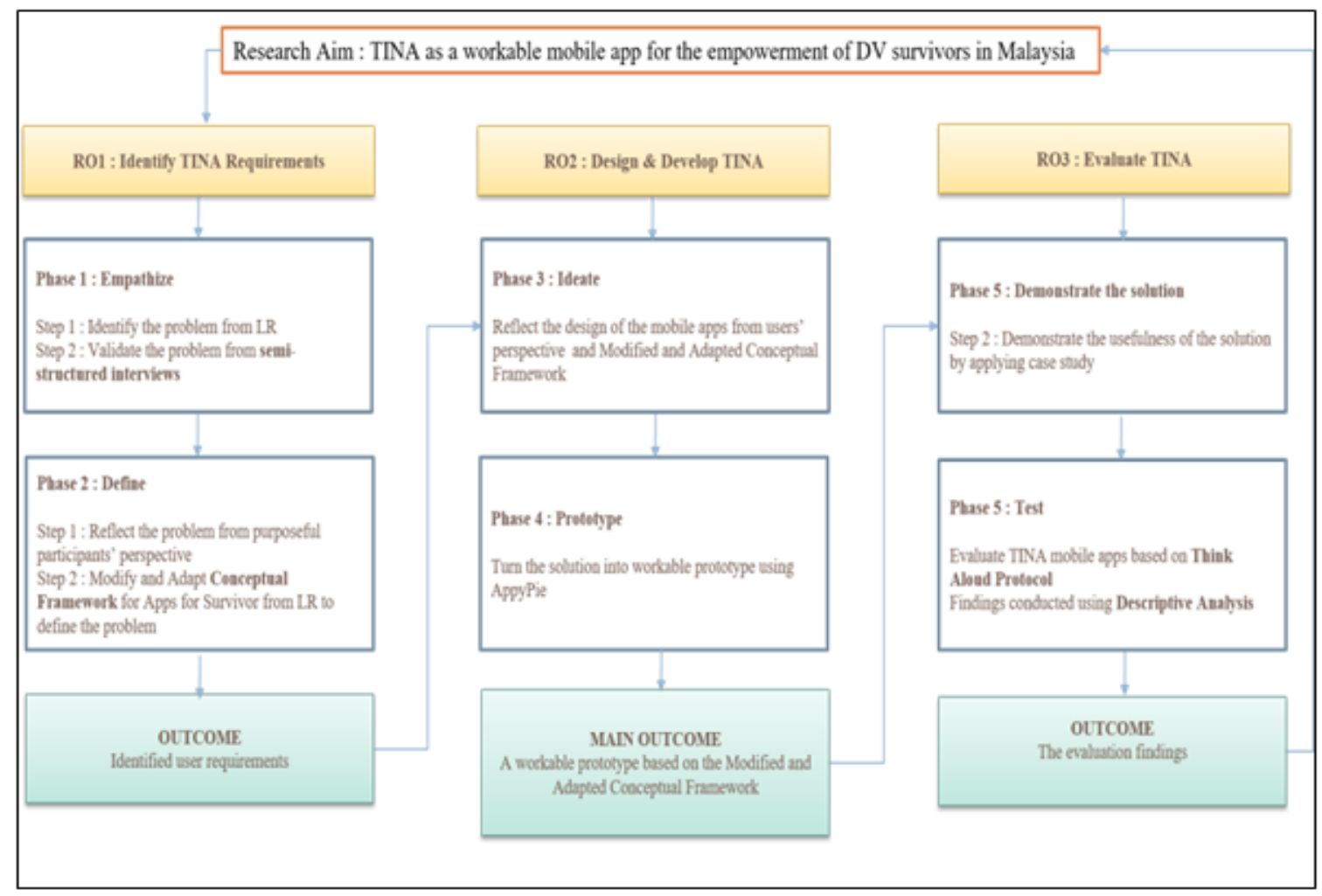

Figure 2. Summary of Research Design

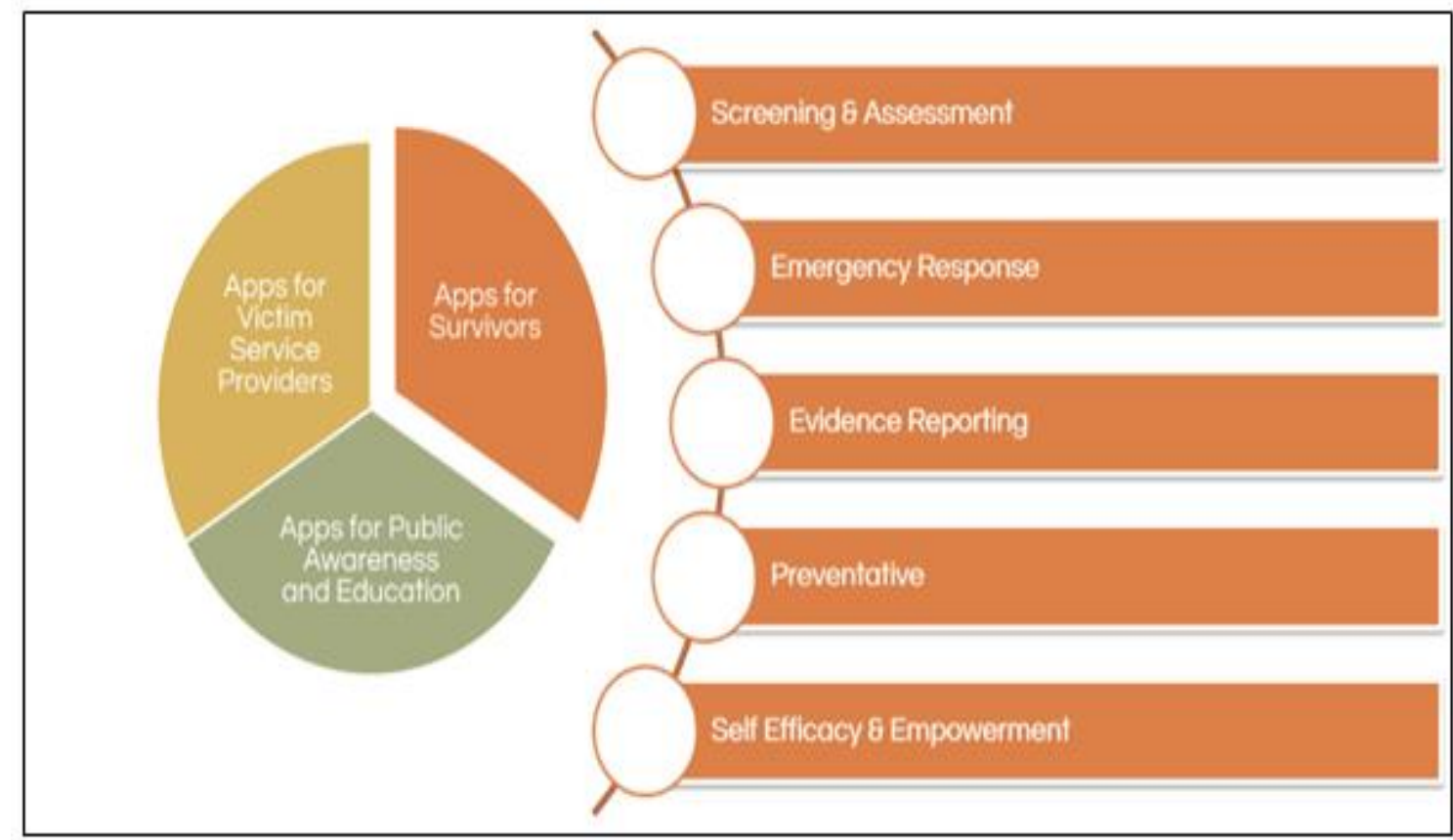

Figure 3. Conceptual Framework of TINA mobile app for DV survivors 
Table 1 .Mapping the Major Themes to TINA Modules and Features

\begin{tabular}{|c|c|c|c|}
\hline No & Major Themes & TINA Modules & TINA Features \\
\hline 1 & $\begin{array}{l}\text { Screening } \\
\text { Assessment }\end{array}$ & $\mid \begin{array}{ll}\text { Quizzes } \\
\checkmark & \text { HITSScreening } \\
\checkmark & \text { Symptoms ofDV }\end{array}$ & Self-Diagnosis Quizzes \\
\hline 2 & $\begin{array}{l}\text { Emergency } \\
\text { Response }\end{array}$ & Hotline & Direct Call to WAO Hotline \\
\hline 3 & Evidence Reporting & $\mid \begin{array}{ll}\text { Tools } \\
\checkmark & \text { Camera } \\
\checkmark & \text { AudioRecorder } \\
\checkmark & \text { VideoRecorder } \\
\checkmark & \text { Diary }\end{array}$ & $\begin{array}{l}\text { Data Collection via Camera, Audio Recorder, } \\
\text { Video Recorder, Online Diary }\end{array}$ \\
\hline 4 & Preventative & \begin{tabular}{|ll} 
Resources \\
$\checkmark$ & All AboutDV \\
$\checkmark$ & GetHelp \\
$\checkmark$ & E-Reader \\
$\checkmark$ & Videos \\
$\checkmark$ & Photos
\end{tabular} & $\begin{array}{l}\text { Education \& Awareness about VAW and DV } \\
\text { via a variety of medium including Text, } \\
\text { Videos and Photos }\end{array}$ \\
\hline \multirow[t]{2}{*}{5} & $\begin{array}{l}\text { Self-Efficacy\& } \\
\text { Empowerment } \\
\text { through Advocacy }\end{array}$ & $\mid$\begin{tabular}{ll}
\multicolumn{1}{l}{ Chat } \\
$\checkmark$ & GroupChat \\
$\checkmark$ & WhatsApp
\end{tabular} & $\begin{array}{l}\text { Counsellingafterdisclosureofabusevia Chat } \\
\text { Board consisting of Group Chats (with other } \\
\text { DV survivors) and WhatsAppChats }\end{array}$ \\
\hline & & $\begin{array}{ll}\text { Contact } \\
\checkmark & \text { Inquiry } \\
\checkmark & \text { Appointment } \\
\checkmark & \text { Events } \\
\checkmark & \text { Directory } \\
\checkmark & \text { TwitterFeed } \\
\checkmark & \text { FacebookFeed } \\
\checkmark & \text { About Us }\end{array}$ & $\begin{array}{l}\text { Awareness of community resources for } \\
\text { victims and survivors: } \\
\text { 1. WAO - inquiry, setting offuture } \\
\text { appointment, events conducted by WAO, } \\
\text { socialmedia } \\
\text { 2. Directory to other NGO / local authorities } \\
\text { hospitals }\end{array}$ \\
\hline 6 & Look \& Feel & $\begin{array}{l}\text { Sign Up Login } \\
\text { User Profile }\end{array}$ & $\begin{array}{l}\text { We also apply Covert Icon for TINA (in the } \\
\text { form of a little girl commissionedby WAO to } \\
\text { artist Wen Li for their published book, entitled } \\
\text { TINA's Journey). This icon is synonymous } \\
\text { with TINA as a brand for WAO, but is still } \\
\text { covert to the male's awareness of issues } \\
\text { pertaining toDV.We also used the Red and } \\
\text { Yellow as the main colors of the app to align } \\
\text { withthe goal of the app. Red to symbolize } \\
\text { love, power,passionandstrength,andYellow to } \\
\text { symbolize hope, positivityandempowerment. }\end{array}$ \\
\hline
\end{tabular}




\section{Results and Discussion}
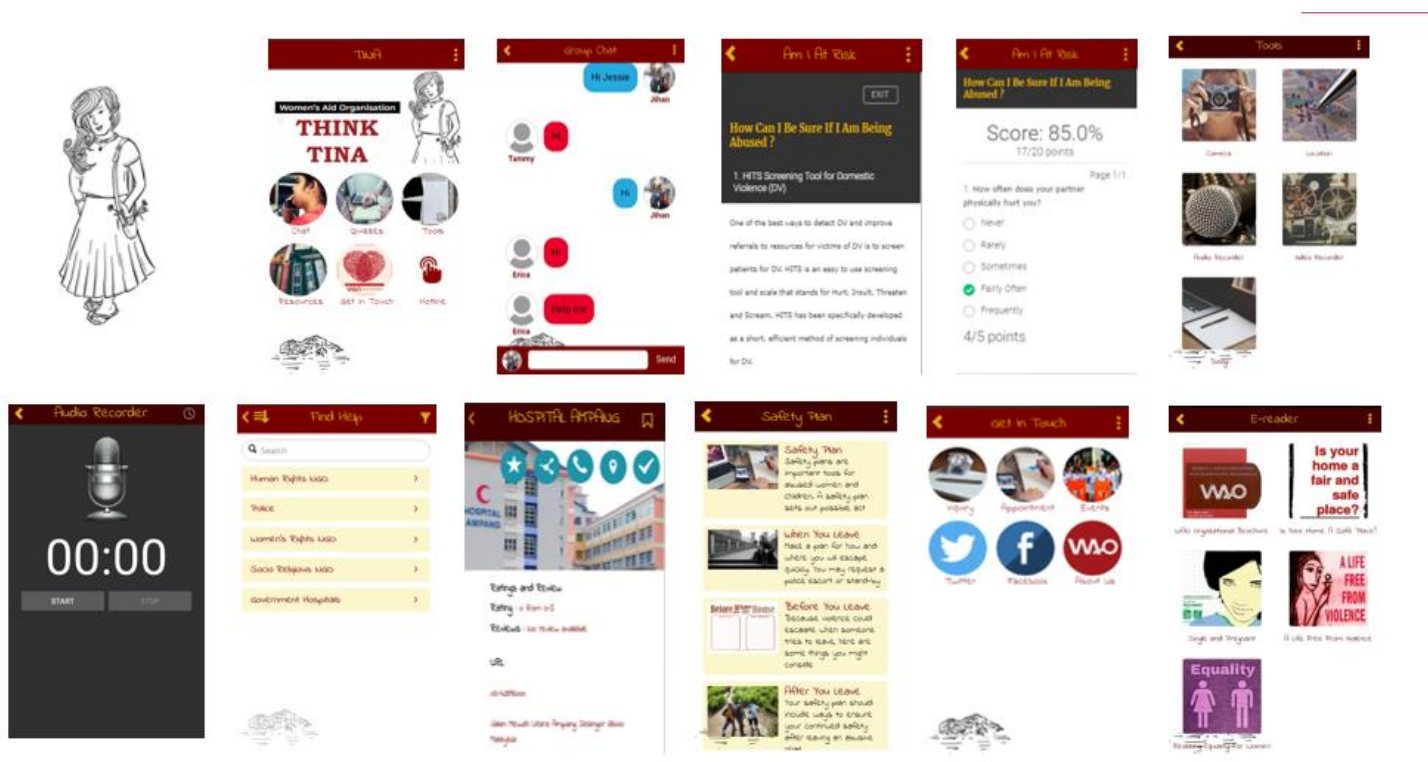

Figure 4.Screen shots of TINA mobile application for DV survivors

The user feedback and recommendation wereanalysed and discussed based on the compiled test observation, recording sheet and transcription of the post mortem test session with the focus group of surrogate users and with DV survivors as the target users. Based on general observation, we found one obvious behaviourobserved throughout the test session: how the actual target users behaved differently from the surrogate users. The actual target users rarely asked questions when completing a task and seemed to understand that the app was developed as a tool to empower them visually and textually. They were generally pleased with the app and stated their first priority of using the app was to feel good about themselves rather than using it as a communication medium. In contrast to the surrogate users, whose main concern was how TINA technically could be used to reach WAO. For the look and feel of TINA, both group of users were pleased with the covertness of the app icon, which does not reflect distress or feminism in the icon design.Both group of users also said they felt empowered and calm after using the app for the first time.

(i) Screening and Assessment -for the actual target users, their main concern was what to do next, i.e. plan of action after a quiz was completed. There should be a sort of safely plan generated after quiz completion to allow a user to course correct her relationship in the case where one who opts to not seek professional help.(ii) Emergency and Response - the function was designed and developed to enable one touch call to WAO Hotline in responding to emergency call, which was agreed upon in the co-creation session. However, upon testing, we were informed by surrogate users that WAO does not function on 24 hours call basis. The recommendation was to bring forward the 'Find Aid' submodule which resides in the Resources module as the main module for Emergency Response. There was also suggestion by surrogate users to put in additional numbers such as the Police Hotline and TalianKasih Hotline by KPWKM. (iii) Evidence Reporting - for the provision of empowerment-based intervention, the functionalities of audio recording, video recording, camera and online journaling were acknowledged by both group of users as being beneficial and a tool to aid the healing process. The tool may also be used as evidence gathering after a traumatic episode for future references. However, the tool maybe misused, i.e. used during live confrontation thus potentially endangering the life the survivor. Recommendation includes a warning message or disclaimer to notify users of the purpose of this module. (iv) Preventative (resources) - generally, surrogate users felt the app was overwhelming with information, which contrast to actual target users, who wanted all the information to be displayed for them to read. They regard the 'Videos', 'Photos' and 'E-Reader' submodules as the most beneficial features of the app as they provided them with encouragement quotes and positivity energy.(v)Self-Efficacy\& Empowerment through Advocacy- The Chat subtheme was very well received by both surrogate users and actual target users. One recommendation by surrogate users was to notify users of the app that the current TINA WhatsApp number should be saved to their smartphones before they are able to WhatsApp WAO from the mobile app.The other recommendation was in regards to Facebook events integration. At present, AppyPie only displays future events from Facebook and does not display past events. The recommendation was for TINA to show past events as well so survivors would know the type of events organized by WAO. 


\section{Conclusion}

The research proposed TINA, a mobile application developmentto empower DV survivors based on our proposed empowerment framework presented in this paper. The development has successfully taken place using Design Thinking method and the feedback received from both group of users; surrogate and actual target users has been reviewed and discussed thoroughly. For the next stage of prototype iteration, we hope to improve the app by incorporating all the feedback. Besides the aforementioned recommendations, we also plan to involve clinicians and psychologists in the data collection and verification of the screening and assessments quizzes in TINA, and to propose the appropriate plan of action after undertaking the self-administered screening and assessments accordingly. TINA can also be improved by re-arranging the app content according to the communication medium and urgency of WAO response to the user's distress level upon app usage. In the end we hope that TINA can be utilised as an empowerment-based intervention platform for DV survivors in Malaysia. We content thatthis work will impact researchers, designers, and developers design explicitly with the empowerment in mind by using the design concepts we offer in this paper.

\section{References}

1. Beyene, A.S., Chojenta, C., Roba, H.S. et al., 2019. Gender-based violence among female youths in educational institutions of Sub-Saharan Africa: a systematic review and meta-analysis. Syst Rev 8, 59.

2. Bivens, R \& Hasinoff, A.A., 2018. Rape: is there an app for that? An empirical analysis of the features of anti-rape apps, Information, Communication \& Society, 21:8.

3. Distress emergency app," Malay Mail Online, 2013. [Online]. Available: http://www.themalaymailonline.com/malaysia/article/cops-say-no-to-reviving-mydistress-emergencyapp. [Accessed: 24-Jan-2019].

4. Digital News Asia, "SecQ.me cuts prices for Watch Over Me personal safety app," Digital News Asia, 2014. [Online]. Available: https://www.digitalnewsasia.com/sizzle-fizzle/secqme-cuts-prices-for-watchover-me-personal-safety-app. [Accessed: 24- Jan-2019].

5. Dunlap, J.A., 2012. Intimate Terrorism and Technology: There's an App for That. University of Massachusetts Law Review, Vol. 7, 2012.

6. Helmy, I., Adawiyah, W. R., \& Banani, A. 2019. Linking Psychological Empowerment, Knowledge Sharing, and Employees' Innovative Behavior in SMEs. The Journal of Behavioral Science, 14(2), 6679.

7. Leech. 2015. "Combating gender-based harassment through mobile," Connected Women. [Online]. Available: http://www.gsma.com/mobilefordevelopment/programme/connected-women/combatinggender-based-harassment-through-mobile. [Accessed: 20-Feb-2020].

8. Hussain, A., Mkpojiogu, E.O.C., Jasin, N.M. (2017). Usability metrics and methods for public transportation applications: A systematic review. Journal of Engineering Science and Technology, 12 (Special Issue 4), pp. 98-105.

9. Hussain, A., Mkpojiogu, E.O.C. (2016). Usability evaluation techniques in mobile commerce applications: A systematic review. AIP Conference Proceedings, 1761, art. no. 020049,

10. P. Dimond, C. Fiesler and A. S. Bruckman, 2011. "Domestic violence and information communication technologies," in Interacting with Computers, vol. 23, no. 5, pp. 413-421.

11. R. Williams, V. Halstead, D. Salani, and N. Koermer. 2016. "Intimate Partner Violence Screening and Response: Policies and Procedures Across Health Care Facilities,” Women's Heal. Issues, vol. 26, no. 4, pp. 377-383.

12. Karapanos, E. 2015. Sustaining user engagement with behavior-change tools. ACM Interactions, 22(4), 48-52.

13. Kementerian Pembangunan Wanita dan Masyarakat (KPWKM). 2015. Garis Panduan Pengendalian Keganasan Rumah Tangga.

14. Knol, J., \& Linge, R. V. 2009. Innovative behaviour: The effect of structural and psychological empowerment on nurses. Journal of Advanced Nursing, 65(2), 359-370.

15. Leech, H. 2015. Combating gender-based harassment through mobile. [Online] Available: http://www.gsma.com/mobilefordevelopment/programme/connected-women/combating-gender- basedharassment-through-mobile[Accessed: 20-Feb-2020].

16. Lockwood, T., \& Papke, E. 2017, Innovation by Design: How Any Organization Can Leverage Design Thinking to Produce Change, Drive New Ideas, and Deliver Meaningful Solutions, Weiser, $1^{\text {st }}$ Edition.

17. L. Tarzia et al. 2016. "I-DECIDE: An Online Intervention Drawing on the Psychosocial Readiness Model for Women Experiencing Domestic Violence,” Women's Heal. Issues, vol. 26, no. 2, pp. 208 216. 
18. M. Abdul-Ghani. 2014. "Exploring Domestic Violence Experiences From The Perspective Of Abused Women in Malaysia," 2014.

19. National Network To End Domestic Violence (NNEDV). 2015. New “App Safety Center" Helps Victims, Advocates Navigate Smartphone Apps. [Online] Available: https://nnedv.org/latest_update/app-safety-center-smartphone/[Accessed: 5-Feb-2019].

20. R. Shuib et al. 2013. "Domestic Violence and Women's Well-being in Malaysia: Issues and Challenges Conducting a National Study Using the WHO Multi-country Questionnaire on Women's Health and Domestic Violence Against Women," Procedia - Soc. Behav. Sci., vol. 91, no. May, pp. 475-488, 2013.

21. Padmapriya \& S.V. Manikanthan, "Retracted: Security and Routing protocol for $5 \mathrm{G}$ wireless mobile networks". IJIMT, 2020.

22. UN General Assembly. 1993. "Declaration on the Elimination of Violence against Women." p. Resolution number: A/RES/48/104, 1993.

23. U.S Department of Defense, "DoD Launches Online Program to Help Military Survivors of Sexual Abuse, Assault," defense.gov, 12-Jun-2017.

24. WAO(a), "Perspectives on Domestic Violence," 2017

25. WAO(b) WAO Statistics 2018 [Online] Available: https://wao.org.my/domestic-violencestatistics/[Accessed: 5-Oct-2019].

26. WHO. 2013. Global and Regional Estimates of Violence against Women: prevalence and health effects of intimate partner violence and non-partner sexual violence Geneva: WHO Online at: http://apps.who.int/iris/bitstream/10665/85239/1/9789241564625_eng.pdf

27. Yeager, D. S., Romero, C., Paunesku, D., Hulleman, C. S., Schneider, B., Hinojosa, C., Dweck, C.S. 2016. Using Design Thinking to Improve Psychological Interventions: The Case of the Growth Mindset During the Transition to High School. Journal of Educational Psychology, 108(3), 374-391.

28. Zimmerman M.A. 2000, Empowerment Theory. In: Rappaport J., Seidman E. (eds) Handbook of Community Psychology. Springer, Boston, MA 